\title{
ANHEMBIA: NOVO GÊNERO DE BIVALVES DO GRUPO PASSA DOIS - PERMIANO
}

\author{
Sérgio MEZZALIRA \\ Josué Camargo MENDES
}

Maria da Saudade A.S. MARANHÃO

\section{RESUMO}

O reexame dos espécimes de bivalves do Grupo Passa Dois (Permiano) referidos inicialmente por MENDES (1949) ao gênero Leinzia, então por ele proposto, e o de novos espécimes coletados no Estado de São Paulo levaram os autores à proposição de um novo gênero, Anhembia, para duas espécies anteriormente atribuídas àquele gênero, $A$ froesi e $A$. gigantea, ambas procedentes da seção inferior da Formação Corumbataí (= Fácies Serra Alta dos Estados do Paraná e Santa Catarina).

\section{ABSTRACT}

The restudy of specimens of bivalves of the Passa Dois Group (Permian) formerly referred by MENDES (1949) to the genus Leinzia and of new specimens collected in the State of São Paulo has led the authors to propose a new genus, Anhembia, for two of the species previously assigned to that genus, $A$. froesi and $A$. gigantea, both of which from the lower section of the Corumbataí Formation of the state of São Paulo (equivalent to the Serra Alta Facies in the states of Paraná and Santa Catarina).

\section{INTRODUÇÃO}

O reestudo de Leinzia froesi e $L$. gigantea (MENDES, 1949), cuja localidade-tipo é a antiga sondagem de Anhembi, Estado de São Paulo, e o exame de exemplares de bivalves atribuídos por MEZZALIRA (1980) a $L$. froe$s i$, procedentes de afloramentos e de testemunho de sondagem de localidades do mesmo Estado, levaram os autores à proposição de um novo gênero, Anhembia, tendo como espécie-tipo $L$. froesi. A esse novo gênero filia-se também $L$. gigantea Mendes, 1949. Desse modo, fica restrita ao gênero Leinzia Mendes, 1949 emend., uma única espécie, $L$. similis, que tem como espécie-tipo Solenomorpha similis Holdhaus, 1918, conhecida até agora somente no Estado do Paraná, Formação Serrinha. O novo gênero apresenta características morfológicas que o distinguem satisfatoriamente de Leinzia.

\section{ESTRATIGRAFIA E LITOLOGIA}

O Grupo Passa Dois tem, nos Estados de São Paulo e Paraná, uma divisão estratigráfica diversa, estando ausentes, no primeiro, as Formações Rio do Rasto e Serrinha e presentes no segundo.

A classificação adotada neste trabalho para o Estado de São Paulo é a seguinte:
Formação Corumbataí (correspondente ao Estrada Nova) Formação Irati

Grupo Passa Dois

A descrição litológica e a divisão dessas formações não serão aqui referidas pois escapam ao objetivo do trabalho. Leinzia similis (Holdhaus) só é conhecida presentemente no Estado do $\mathrm{Pa}$ raná, em arenito esbranquiçado e arenito-síltico cinza-esverdeado, bem estratificado, ao passo que "Leinzia" froesi e 'L." gigantea Mendes só foram encontrados, até a presente data, no Estado de São Paulo. As matrizes dos seus holótipos e parátipos são constituídas por um siltito fino cinza-escuro e procedem das sondagens de $n$ ? s 3 e 4 levadas a efeito em Anhembi, município de Anhembi, pela Cia. Brasileira de Sondagem.

Os exemplares ora assinalados, em afloramentos e testemunhos de sondagem, associados aos de Anhembi, servem de base para a proposição do novo gênero e têm como matriz um siltito fino avermelhado e arroxeado, no caso dos procedentes dos afloramentos, e um siltito fino cinza-claro, no caso dos da sondagem. Os novos espécimes procedem da região de CordeirópolisRio Claro e da sondagem de Laras, profundidade de $130 \mathrm{~m}$, município de Laranjal Paulista. Todos os exemplares ocorrem na base da Formação Corumbataí. 


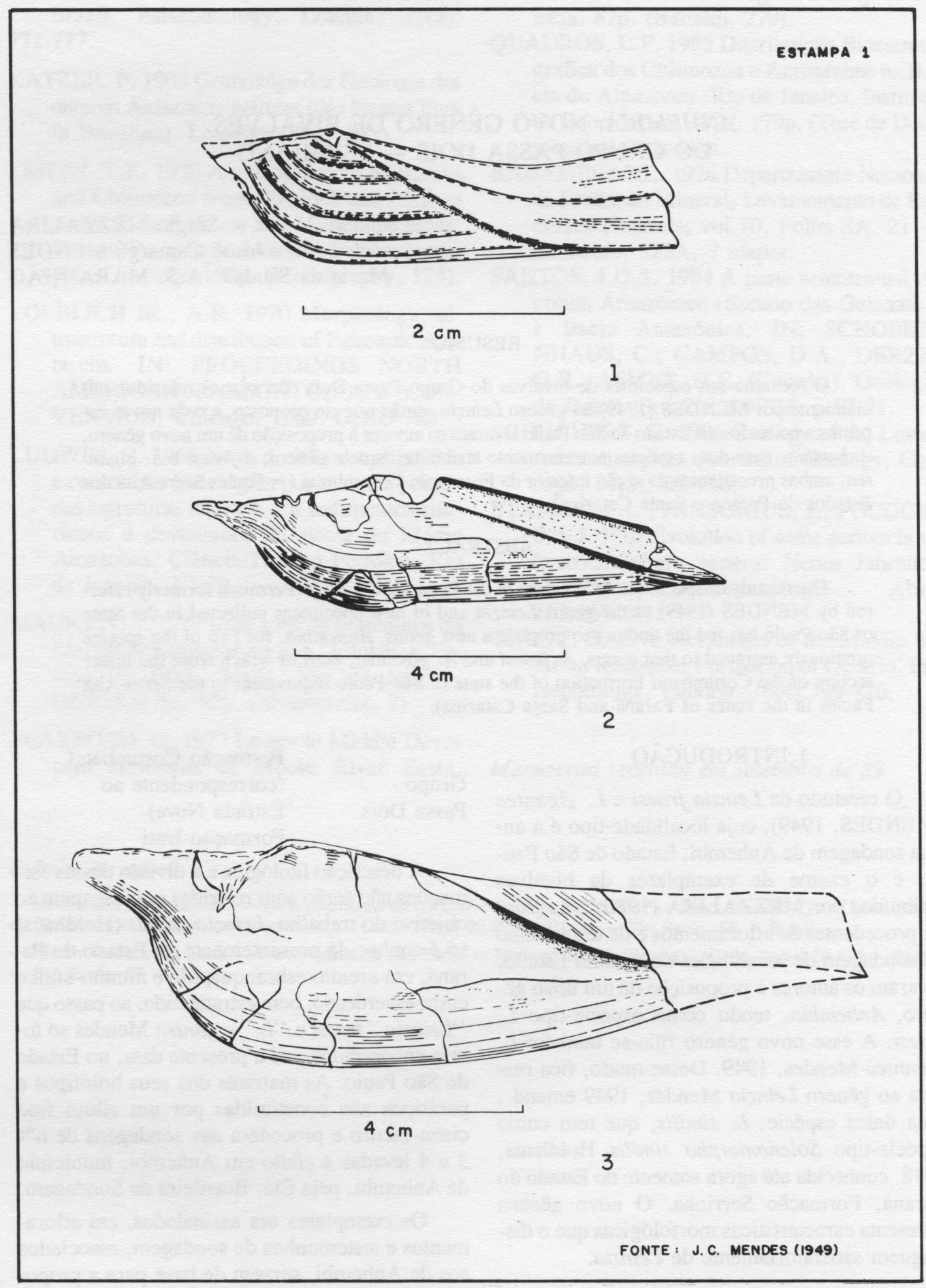

\section{EXPLICAÇÃO DA ESTAMPA 1}

Fig. 1 - Leinzia similis (Holdhaus, 1918). Contramolde externo de um indivíduo com as valvas conjugadas, estando a da direita deslocada para cima. Formação Serrinha.

Km 109+80m da Estrada Ponta Grossa-Guarapuava, Estado do Paraná. № DGP - VII 86 da coleção do Instituto de Geociências da USP.

Fig. 2 - Anhembia froesi (Mendes, 1949). Holótipo; contramolde externo de uma valva esquerda. Fácies Serra Alta. Anhembi, município de Anhembi, SP. No DGP - VII 89 da coleção do Instituto de Geociências da USP.

Fig. 3 - Anhembia gigantea (Mendes, 1949). Holótipo; contramolde externo de uma valva esquerda. Fácies Serra Alta. Anhembi, município de Anhembi, SP. № DGP - VII 91 da coleção do Instituto de Geociências da USP. 
O gênero Leinzia Mendes emend. é característico da Formação Serrinha, Estado do Paraná, enquanto Anhembia o é da seção inferior da Formação Corumbataí correspondente à fácies Serra Alta. A Formação Serrinha sugere condições de águas agitadas, enquanto a fácies Serra Alta representa uma deposição em ambiente de águas pouco agitadas e levemente redutoras, pois suportavam vida bentônica (bivalves e conchostráceos).

\section{DESCRIÇÃO DO MATERIAL}

A revisão permitiu a proposição do novo gênero Anhembia com as espécies $A$. froesi (Mendes, 1949) e A. gigantea (Mendes, 1949).

ANHEMBIA gen. nov.

Espécie-tipo: Leinzia froesi (Est. 1, Fig. 2) Mendes, 1949

Diagnose: Concha de tamanho médio a grande, transversalmente alongada, ovalada-lanceolar, inequilátera, equivalva (?), mais larga na parte anterior estreitando-se na parte posterior. Carena posterior oblíqua sub-reta a encurvada com a concavidade voltada para o alto, indo do umbo à extremidade caudal. Umbo situado próximo do bordo anterior. Ângulo ântero-dorsal dotado de uma aleta bastante pronunciada. Superfície ornamentada com finas linhas de crescimento, ausentes na área da carena. Charneira alongada. Dimiária. Outros caracteres internos desconhecidos.

Material: Moldes e contramoldes externos e internos de valva esquerda e direita.

Procedência: 1 - Anhembi, testemunho de sondagem dos poços nos 3 e 4 da Cia. Brasileira de Sondagem. Município de Anhembi;

2 - Km 163 da Via Washington Luiz. Município de Cordeirópolis;

3 - Km 7 da estrada velha Rio Claro - Piracicaba. Município de Rio Claro e

4- Laras, testemunho de sondagem do poço 2-IG, profundidade $130 \mathrm{~m}$. Município de Laranjal Paulista. Todas as localidades são do Estado de São Paulo.

Derivação do nome: A designação genérica baseou-se no nome da cidade de Anhembi, sede do município homônimo.

Medidas: 1 - Espécimes-tipos de Anhembi. №s DGP-VII 89 e DGP-VII 91 da coleção do IG-USP.

\section{Anhembia froesi}

(Mendes)

(est. 1, fig. 2)

Comprimento $(\mathrm{C})=$

$80 \mathrm{~mm}$ (presumidos)
$(78,5 \mathrm{~mm}$ medidos na

(93mm medidos na parte conservada)

parte conservada)

2 - Anhembia froesi (Mendes, 1949). Molde externo, valva esquerda. № 611-I da Coleção do IGSMA. Km 7 da estrada velha Rio ClaroPiracicaba, município de Rio Claro.

Comprimento $(\mathrm{C})=80 \mathrm{~mm}$

Altura $(\mathrm{A})=23 \mathrm{~mm}$

Relação A/C $=28,75 \%$

Expansão pteróide $=15 \mathrm{~mm}$

3 - Anhembia froesi (Mendes, 1949). Molde externo, valva esquerda. № 661-I da Coleção do IGSMA. Km 163 da Via Washington Luiz, município de Cordeirópolis.

Comprimento $(\mathrm{C})=90 \mathrm{~mm}$

Altura $(A)=25 \mathrm{~mm}$

Relação A/C $=27,7 \%$

Expansão pteróide $=15 \mathrm{~mm}$

4 - Anhembia froesi (Mendes, 1949). Molde interno, valva direita. № 774-I da Coleção do IGSMA. Laras, município de Laranjal Paulista.

Comprimento $(\mathrm{C})=32 \mathrm{~mm}$ (Provável forma jovem)

Altura (A) $=9 \mathrm{~mm}$

Relação $\mathrm{A} / \mathrm{C}=28,12 \%$

Expansão pteróide $=6 \mathrm{~mm}$

Discussão: O gênero, ora proposto, apresenta algumas similaridades com Leinzia, mas se diferencia principalmente pela forma ovalar, ausência de costelas concêntricas e expansão pteróide ântero-dorsal maior, chegando a alcançar de 16 a $20 \%$ do comprimento total da concha. As extensões pré e pós-umbonais da margem dorsal de Anhembia formam entre si um ângulo variável de 140 a $160^{\circ}$ ao passo que, em Leinzia similis, esse ângulo é mais obtuso.

MENDES (1949) já assinalara algumas dessas divergências, sem entretanto propor uma separação genérica entre $L$. similis (est. 1, fig. 1) e as duas outras espécies então atribuídas também a Leinzia.

Entre as duas espécies Anhembia froesi (Mendes, 1949) e $A$. gigantea (Mendes, 1949) há algumas características diferentes, a saber: a gigantea diferencia-se de froesi pelo seu tamanho superior, maior convexidade anterior, bordo dorsal sub-reto, umbo mais volumoso e ornamentação ligeiramente mais acentuada.

A relação $A \times 100$ varia em Anhembia de C

25 a $28,75 \%$ e em Leinzia de 26 a $32 \%$.

\section{LEINZIA Mendes, 1949 emend.}

Concha transversalmente alongada, ovatolanceolada, pronunciadamente inequilátera, mais larga anteriormente, estreitando-se na parte posterior. Carena posterior, oblíqua, indo do umbo 
à extremidade caudal. Umbo situado próximo ao bordo anterior. Ângulo ântero-dorsal dotado de uma expansão pteróide mais ou menos pronunciada. Superfície ornamentada com costelas subconcêntricas, ausentes na área acima da carena. Charneira alongada, apresentando, na região cardinal, um dente único, oblíquo. Ligamento opistodético.

\section{BIOESTRATIGRAFIA}

O espécime de Anhembia froesi (Mendes, 1949) procede da profundidade de $107,5 \mathrm{~m}$ da sondagem n 0.3 e está a cerca de $32 \mathrm{~m}$ acima do topo do Irati e o de Anhembia gigantea (Mendes, 1949), holótipo da profundidade de $177,60 \mathrm{~m}$ e o parátipo da de $163 \mathrm{~m}$, ambos da sondagem no. 4, situando-se, portanto, a 21 e $25 \mathrm{~m}$ respectivamente acima do topo do Irati, estando todos os exemplares, localmente, na base da Formação Corumbataí, dentro da fácies Serra Alta.

A sondagem do poço 2-IG, em Laras, acusou o seguinte perfil:
, i

0 a $10 \mathrm{~m}$ - Solo com seixos de sílex

10 a 135 m - Sedimentos Corumbataí (102 a 135m-siltitos do Serra Alta)

135 a $174,5 m$ - Sedimentos do Irati

174,5 a 231 m - Sedimentos do Grupo Tubarão.

O espécime de Anhembia de Laras foi encontrado à profundidade de $130 \mathrm{~m}$, portanto a cerca de $5 \mathrm{~m}$ acima do topo do Irati, sendo a espessura do Corumbataí, atravessada nessa sondagem, de $125 \mathrm{~m}$. Os assinalados na região de Cordeirópolis - Rio Claro estão situados há algumas dezenas de metros acima do topo do Irati e na parte basal da Formação Corumbataí. Em uma mesma amostra está presente, também, Barbosaia sp., indicativa da porção basal da referida formação geológica.

Em vista de Leinzia froesi Mendes ter sido elevada à categoria de espécie-tipo do novo gênero Anhembia, a Zona Leinzia froesi Mendes, in MEZZALIRA (1980), e a Zona Leinzia froesi Mendes e Barbosaia angulata Mendes, in MARANHÃO (1986), devem ser agora denominadas de Anhembia froesi (Mendes) e de Anhembia froesi (Mendes) - Barbosaia angulata Mendes, respectivamente.

\section{REFERÊNCIAS BIBLIOGRÁFICAS}

HOLDHAUS, K. 1918 Sobre alguns lamellibranquios fósseis do Sul do Brasil. Rio de Janeiro, DNPM/SGM. 24p. (Monografia, 2)

MARANHÃO, M.S.A.S. 1986 Contribuição ao conhecimento da Malacofauna das camadas basais da Formação Corumbataí (Permiano) Estado de São Paulo. São Paulo, Instituto de Geociências/USP. 88p. (Dissertação de Mes- trado). Inédita.

MENDES, J.C. 1949 Novos lamelibrânquios fósseis da Série Passa Dois (Sul do Brasil). Rio de Janeiro, DNPM/DGM. 40p. (Boletim, 133). MEZZALIRA, S. 1980 Bioestratigrafia do Grupo Passa Dois no Estado de São Paulo. Revista do Instituto Geológico, São Paulo, l(1):15-34.

Manuscrito recebido em março de 88 